\title{
Characterization and Distribution of Two Races of Phialophora gregata in the North-Central United States
}

\author{
T. C. Harrington, J. Steimel, F. Workneh, and X. B. Yang
}

Department of Plant Pathology, Iowa State University, Ames 50011.

Current address of F. Workneh: Texas A\&M University, Texas Agricultural \& Experimental Station, 2301 Experiment Station Road, Bushland 79012.

Accepted for publication 1 March 2003.

\begin{abstract}
Harrington, T. C., Steimel, J., Workneh, F., and Yang, X. B. 2003. Characterization and distribution of two races of Phialophora gregata in the north-central United States. Phytopathology 93:901-912.

Genetic variation and variation in aggressiveness in Phialophora gregata f. sp. sojae, the cause of brown stem rot of soybean, was characterized in a sample of 209 isolates from the north-central region. The isolates were collected from soybean plants without regard to symptoms from randomly selected soybean fields. Seven genotypes (A1, A2, A4, $\mathrm{A} 5, \mathrm{~A} 6, \mathrm{M} 1$, and M2) were distinguished based on DNA fingerprinting with microsatellite probes $(\mathrm{CAT})_{5}$ and $(\mathrm{CAC})_{5}$, with only minor genetic variation within the A or M genotypes. Only the A1, A2, and M1 genotypes were represented by more than one isolate. The A genotypes dominated in the eastern Iowa, Illinois, and Ohio samples, whereas the M genotypes were dominant in samples from western Iowa, Minnesota, and Missouri. In growth chamber experiments, isolates segregated into two

respectively, to brown stem rot. In both root dip inoculation and inoculation by injecting spores into the stem near the ground line (stab inoculations), isolates of the A genotypes caused greater foliar symptoms and more vascular discoloration than isolates of the $\mathrm{M}$ genotypes on both cultivars of soybean. All isolates caused foliar symptoms in both cultivars and in three additional cultivars of soybean with resistance to brown stem rot. Greater differences between the A and M genotypes were seen in foliar symptoms than in the linear extent of xylem discoloration, and greater differences were seen in Kenwood than in BSR101. Inoculation of these genotypes into five cultivars of soybean with different resistance genes to brown stem rot showed a genotype $\times$ cultivar interaction. A similar distinction was found in an earlier study of the adzuki bean pathogen, P. gregata f. sp. adzukicola, and consistent with the nomenclature of that pathogen, the soybean pathogens are named the aggressive race (race A) and the mild race (race M) of $P$. gregata f. sp. sojae.
\end{abstract} pathogenicity groups based on their aggressiveness toward soybean cvs. Kenwood and BSR101, which are relatively susceptible and resistant,
Additional keyword: Glycine max.
Although brown stem rot (BSR) has been considered one of the most important diseases of soybean (Glycine max (L.) Merr.) in the north-central region of the United States (34), the disease is still poorly known, especially concerning variation in aggressiveness of the causal agent, Phialophora gregata (Allington and Chamberlain) Gams. The disease in the north-central region is known by a browning of the vascular system and pith and by characteristic chlorosis and necrosis of the foliage $(1,10,28)$. However, similar vascular discoloration is found late in the season with other diseases of soybean (15), and some strains of the causal agent have been reported to cause vascular discoloration without foliar symptoms (9). Some BSR resistant soybean germ plasm is available $(2,7,13,24,26,30,31)$, mostly identified by the extent of vascular browning of inoculated plants or plants exposed to natural inoculum in the field. However, the development and deployment of resistant cultivars have been hampered by imprecise resistance rating systems, confusion over the identity of some isolates recovered from diseased plants, and the apparent variation in aggressiveness among isolates of $P$. gregata from various geographic regions.

Two special forms of $P$. gregata are recognized: $P$. gregata f. sp. adzukicola on adzuki bean and $P$. gregata f. sp. sojae on soybean (20). Gray (9) reported that the disease in soybean is caused by either of two forms of $P$. gregata, a defoliating form (type I) and a nondefoliating form (type II), with the latter causing vascular

Corresponding author: T. C. Harrington; E-mail address: tcharrin@iastate.edu

Publication no. P-2003-0519-02R

(C) 2003 The American Phytopathological Society discoloration but no foliar symptoms. Although the terminology has not always been consistently applied, variation in pathogenicity within $P$. gregata f. sp. sojae has been noted by many $(12,15$, 23,27,29,32). P. gregata was distinguished from Plectosphaerella sp. and other soybean fungi using molecular techniques $(3,15)$, and two types of $P$. gregata seemed apparent based on inoculations (14) and molecular markers (3-5,22). More recently it was shown that two major genotypes of $P$. gregata $\mathrm{f}$. sp. sojae differ in their pathogenicity to several cultivars of soybean (16). There thus appear to be at least two major genotypes of the BSR pathogen in the north-central region, types A and B sensu Chen et al. (5), and these genotypes appear to correspond with types I and II of Gray (9).

Our purpose was to see if there are more than two genetic variants of $P$. gregata f. sp. sojae using DNA fingerprinting markers and determine their aggressiveness to soybean cultivars with and without resistance to BSR. A large, random sample of isolates from soybean stems, without regard to foliar symptoms, was taken from five north-central states to more fully study the genetic and phenotypic variation in the fungus. We also compared inoculation techniques and propose methods for screening for cultivar resistance.

\section{MATERIALS AND METHODS}

Isolates. We used the semiselective medium of Mengistu et al. (25) to isolate $P$. gregata from soybean stems collected from randomly selected soybean fields in the north-central region at the end of the 1995 and 1996 field seasons $(15,33)$. Stems of soybeans without foliage were sampled at random immediately before or 
after harvest, and isolations were made from stems whether or not they showed vascular browning indicative of BSR. Thus, there was no bias for isolates from plants or fields showing foliar symptoms. After incubation at $15^{\circ} \mathrm{C}$, representative isolates of $P$. gregata, mostly from discolored stems, were subcultured and
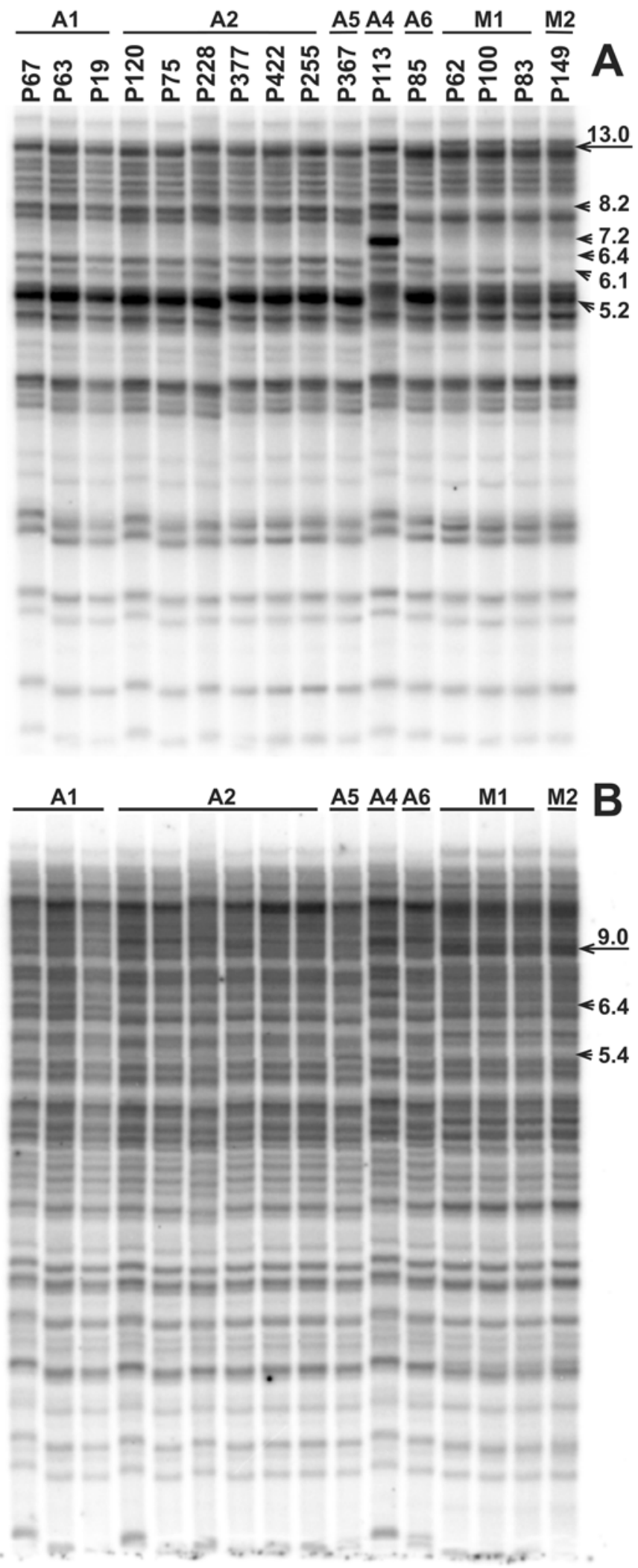

Fig. 1. DNA fingerprinting bands of the aggressive and mild genotypes of Phialophora gregata based on Pst $\mathrm{I}$ digests and hybridization with ${ }^{32} \mathrm{P}$ labeled oligonucleotides $\mathbf{A},(\mathrm{CAT})_{5}$ and $\mathbf{B},(\mathrm{CAC})_{5}$, respectively. Approximate sizes (kilobases) are indicated for the polymorphic bands. stored. All isolates were confirmed as $P$. gregata based on restriction fragment length polymorphisms (RFLPs) of the internal transcribed spacer (ITS) region of the nuclear rDNA (15). The isolates were maintained at $-80^{\circ} \mathrm{C}$ in $15 \%$ glycerol until use. From this collection of more than 450 isolates, 209 isolates, mostly from the 1995 field samples, were selected to represent the widest possible geographic sampling. We studied an additional eight isolates from Wisconsin that were provided by C. Grau, but these were not randomly selected.

DNA fingerprinting. Isolates were grown in liquid culture at $18^{\circ} \mathrm{C}$ for 3 weeks in phosphoglucomutase (PGM) medium (25) but without agar, copper sulfate, pentachloronitrobenzene, or $\mathrm{pH}$ adjustment. Total genomic high-molecular-weight DNA was extracted from all isolates by a slightly modified version of the technique described by DeScenzo and Harrington (6). Restriction digests of dilute preparations of the total genomic DNA using the enzyme PstI (5 units per $\mu \mathrm{g}$ of genomic DNA) followed the procedures described by DeScenzo and Harrington (6). This was followed by separation of the DNA fragments on $1 \%$ agarose gels in $1 \times$ Tris-borate-EDTA. Gels were run, with constant stirring of the buffer, at $88 \mathrm{~V}$ for $17.5 \mathrm{~h}$. Markers ( $1 \mu \mathrm{g}$ of $\lambda$ HindIII DNA) were included in the outside lanes. Gels were stained for $15 \mathrm{~min}$ in ethidium bromide on a rotary shaker, destained in water for $30 \mathrm{~min}$, and visualized under UV light. The gels were dried with a gel drier for $60 \mathrm{~min}$ at $50^{\circ} \mathrm{C}$, sealed in plastic wrap, and stored at $4^{\circ} \mathrm{C}$ until further use.

The 15-bp oligonucleotides $(\mathrm{CAT})_{5}$ or $(\mathrm{CAC})_{5}$ were end-labeled with ${ }^{32} \mathrm{P}-\mathrm{dCTP}$ using polymerase terminal deoxynucleotidyl transferase (Invitrogen, Carlsbad, CA), purified through a Sephadex G25 column, and used as a probe for in-gel hybridization. Hybridization and washing conditions were as described previously (6). Gels were wrapped between two layers of plastic wrap and visualized in either of two ways. Some gels were exposed to a PhoshorImager screen (Molecular Dynamics, Sunnyvale, CA) for 1 to 2 days. The other gels were exposed to X-ray film. Molecular weights of the polymorphic bands were determined using FragmeNT software (Molecular Dynamics).

Each isolate was fingerprinted in at least two gel runs. Bands were scored as present or absent, and only bands that could be clearly and consistently scored for all isolates in all gel runs were used for analyses. For each isolate, only bands that could be clearly scored in at least two different gels were used. Each unique combination of polymorphic bands was considered a genotype. Genotypes were further analyzed using Nei's genetic distance and unweighted pair-group method with arithmetic average (UPGMA) (PHYLIP version 3.573C; J. Felsentein, Department of Genetics, University of Washington, Seattle), assuming that each band was a locus with two alleles, present or absent.

Stab inoculation. Seedlings were inoculated according to the method described in Harrington et al. (15). Fifteen days prior to inoculation, seeds of cvs. BRS101 or Kenwood were planted in autoclaved potting mix (1:2:2, soil/peat/perlite) in 15-cm-diameter pots in growth chambers set at $21^{\circ} \mathrm{C}$ and 14-h light (330 to $430 \mu \mathrm{E} \mathrm{m}^{-2} \mathrm{~s}^{-1}$ ). When the plants were 15 days old, at the v1 to v2

TABLE 1. Seven genotypes of Phialophora gregata based on the presence $(1)$ or absence $(0)$ of $(\mathrm{CAT})_{5}$ and $(\mathrm{CAC})_{5}$ fingerprint bands ${ }^{\mathrm{a}}$

\begin{tabular}{|c|c|c|c|c|c|c|c|}
\hline \multirow[b]{2}{*}{ Genotype } & \multicolumn{5}{|c|}{$(\mathrm{CAT})_{5}$} & \multicolumn{2}{|c|}{$(\mathrm{CAC})_{5}$} \\
\hline & 5.2 & 6.1 & 6.4 & 7.2 & 8.2 & 5.4 & 6.4 \\
\hline A1 & 1 & 1 & 1 & 0 & 1 & 0 & 1 \\
\hline $\mathrm{A} 2$ & 1 & 1 & 1 & 0 & 1 & 0 & 0 \\
\hline A4 & 0 & 1 & 1 & 1 & 1 & 0 & 0 \\
\hline A5 & 1 & 1 & 1 & 0 & 1 & 1 & 0 \\
\hline A6 & 1 & 1 & 1 & 0 & 0 & 0 & 0 \\
\hline M1 & 0 & 1 & 0 & 0 & 0 & 0 & 0 \\
\hline M2 & 0 & 0 & 0 & 0 & 0 & 0 & 0 \\
\hline
\end{tabular}

a Approximate band sizes (kilobases) are indicated. 
growth stage (8), they were thinned to three per pot immediately prior to inoculation. All three stems in one pot were inoculated with the same isolate or with control inoculum.

The isolates were grown in the dark at $18^{\circ} \mathrm{C}$ for 3 weeks on PGM medium. Inoculum, consisting of hyphae, conidiophores, and conidia, was scraped from the agar surface into a homogeneous slurry. A small amount of the slurry was collected with the tip of a sterile syringe needle (22-gauge) and stabbed into the main stem of a soybean seedling at 1 to $2 \mathrm{~cm}$ above the soil line. Using a hemacytometer, we determined that a range of 2.2 to $8.0 \times 10^{4}$ spores of $P$. gregata were picked up by the needle (15). Control plants were similarly treated with scrapes of sterile PGM.

The growth chamber temperature was then set to $17^{\circ} \mathrm{C}$, and the plants were fertilized at 1 and 3 weeks after inoculation with $1 \mathrm{~g} /$ liter of 20-10-20 fertilizer. Five weeks after inoculation, the plants were harvested and assessed for the incidence of chlorotic or necrotic leaflets. The linear extent of vascular browning was determined by cutting lengthwise into the stems with a scalpel and measuring from the inoculation wound to the highest point of discernable discoloration. Stem diameter was determined by a metric dial caliper, with $0.1-\mathrm{mm}$ increments, at the stem's thickest point, just above ground level.

For each experiment, there were two replications (two pots per cultivar $\times$ isolate combination; one pot in each of two growth chambers), and each experiment was repeated. Means of the three plants per pot were used in analyses. An arcsine transformation of the percent leaflets symptomatic was used to normalize the data for analyses. Analysis of variance (ANOVA) was used to determine if there was variation among treatments. The treatment means were separated with Duncan's multiple range test or by linear contrasts. All statistical analyses were conducted with the use of SAS software (SAS Institute, Cary, NC).

Root dip inoculation. Nine representative isolates were used in inoculations of cvs. Kenwood and BSR101 by two inoculation methods, the stab method described previously and a root dip method. Isolates used were P19, P21, P31, P63, and P106 (A genotypes), and P30, P82, and P92 (M genotypes).

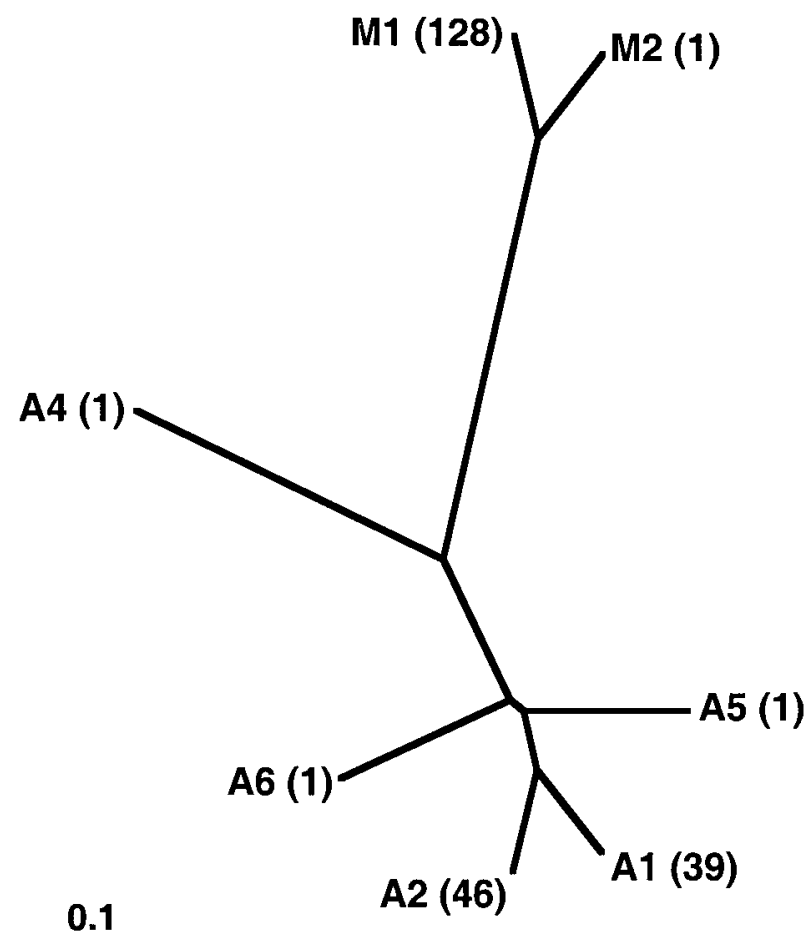

Fig. 2. Unrooted UPGMA tree of the seven DNA fingerprinting genotypes of Phialophora gregata. The number of isolates of each genotype is indicated in parentheses, and the bar length is proportional to genetic distance.
Plants were grown as described previously. Inoculum for the root dip method was scraped from 3-week-old cultures of each isolate grown on PGM medium with a sterile spatula and suspended in 50 to $100 \mathrm{ml}$ of sterile distilled water. The spore conlcentration was determined with a hemacytometer and was adjusted to a final concentration of 2.3 to $8.1 \times 10^{5}$ spores per $\mathrm{ml}$ in $200 \mathrm{ml}$ of sterile water contained in a 400-ml sterile beaker. Fifteen-day-old seedlings of each cultivar (v1 to v2 stage) were carefully removed from the pots, and after the soil was rinsed off, the roots were trimmed back to $11 \mathrm{~cm}$ under sterile water. The roots were immersed in the spore suspension for $10 \mathrm{~min}$ in the growth chamber under light. The beakers were agitated frequently to keep the spores suspended. Control seedlings were treated similarly but dipped into a solution containing slurry from sterile PGM plates. The plants were planted back into pots (three plants per pot and two pots per cultivar $\times$ isolate combination, one pot in each of two growth chambers). The experiment was repeated.

TABLE 2. Incidence of the seven genotypes of Phialophora gregata found in random soybean samples from fields in five states of the North-Central Region

\begin{tabular}{lrrrcrrrr}
\hline & \multicolumn{7}{c}{ Genotype $^{\mathrm{a}}$} & \\
\cline { 2 - 6 } Field & A1 & A2 & A4 & A5 & A6 & M1 & M2 & Total \\
\hline Iowa & 19 & 17 & 1 & 0 & 0 & 83 & 1 & 121 \\
Illinois & 8 & 11 & 0 & 0 & 1 & 2 & 0 & 22 \\
Minnesota & 1 & 1 & 0 & 0 & 0 & 22 & 0 & 24 \\
Missouri & 2 & 3 & 0 & 1 & 0 & 13 & 0 & 19 \\
Ohio & 5 & 11 & 0 & 0 & 0 & 7 & 0 & 18 \\
Wisconsin & 4 & 3 & 0 & 0 & 0 & 1 & 0 & 8 \\
Total & 39 & 46 & 1 & 1 & 1 & 128 & 1 & 217 \\
\hline
\end{tabular}

${ }^{\mathrm{a}}$ Based on presence or absence of $(\mathrm{CAT})_{5}$ and $(\mathrm{CAC})_{5}$ fingerprint bands.

${ }^{b}$ The eight isolates from Wisconsin were not randomly sampled.

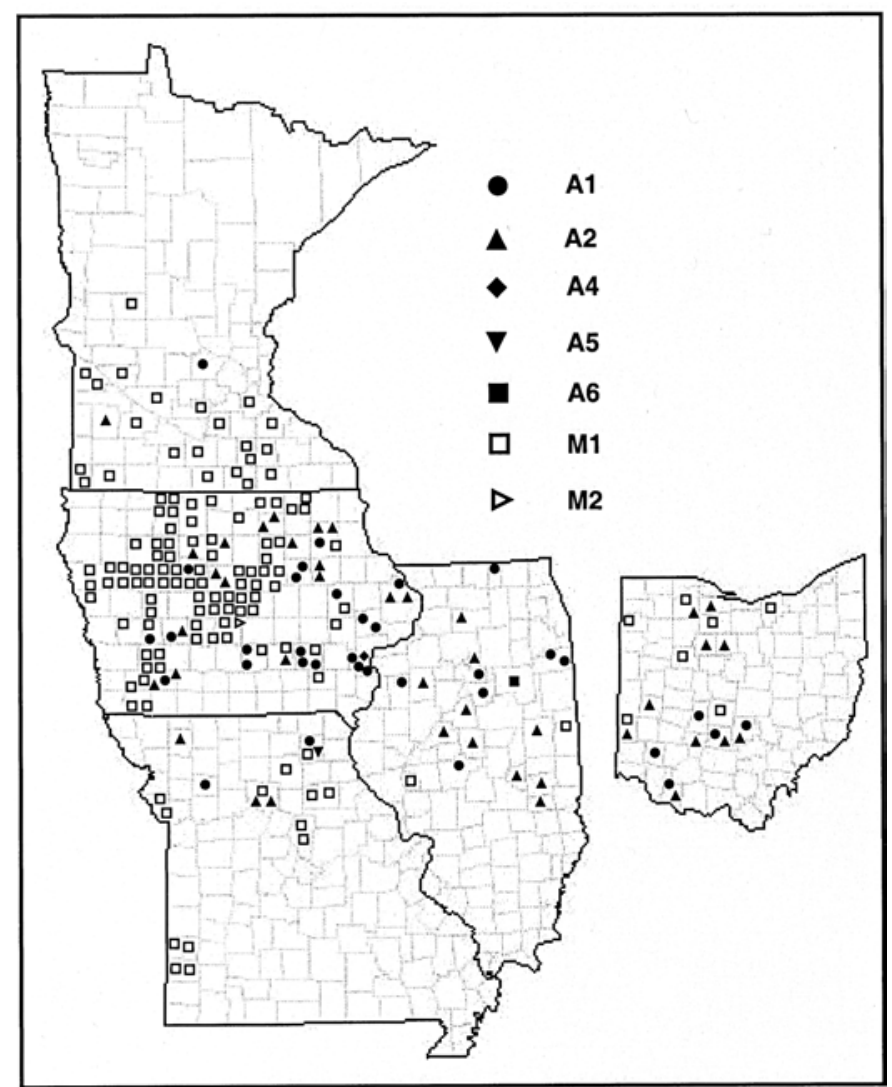

Fig. 3. Geographic distribution of isolates of the seven DNA fingerprint groups among 199 randomly sampled isolates of Phialophora gregata from five states in the north-central region of the United States. 


\section{RESULTS}

DNA fingerprint groups. Only five polymorphic bands were observed in $(\mathrm{CAT})_{5}$ fingerprints and two polymorphic bands in $(\mathrm{CAC})_{5}$ fingerprints among the 217 isolates tested (Fig. 1). A few other bands appeared to be polymorphic but could not be scored in each replicate run, and thus, these bands were excluded from analyses. For instance, the $13.0-\mathrm{kb}(\mathrm{CAT})_{5}$ band was seen in some isolates in some runs (Fig. 1), but the band was absent in the same isolates in other runs. In (CAC) $)_{5}$ fingerprints, there was a $9.0-\mathrm{kb}$ band that could not be scored in all runs (Fig. 1). An additional 18
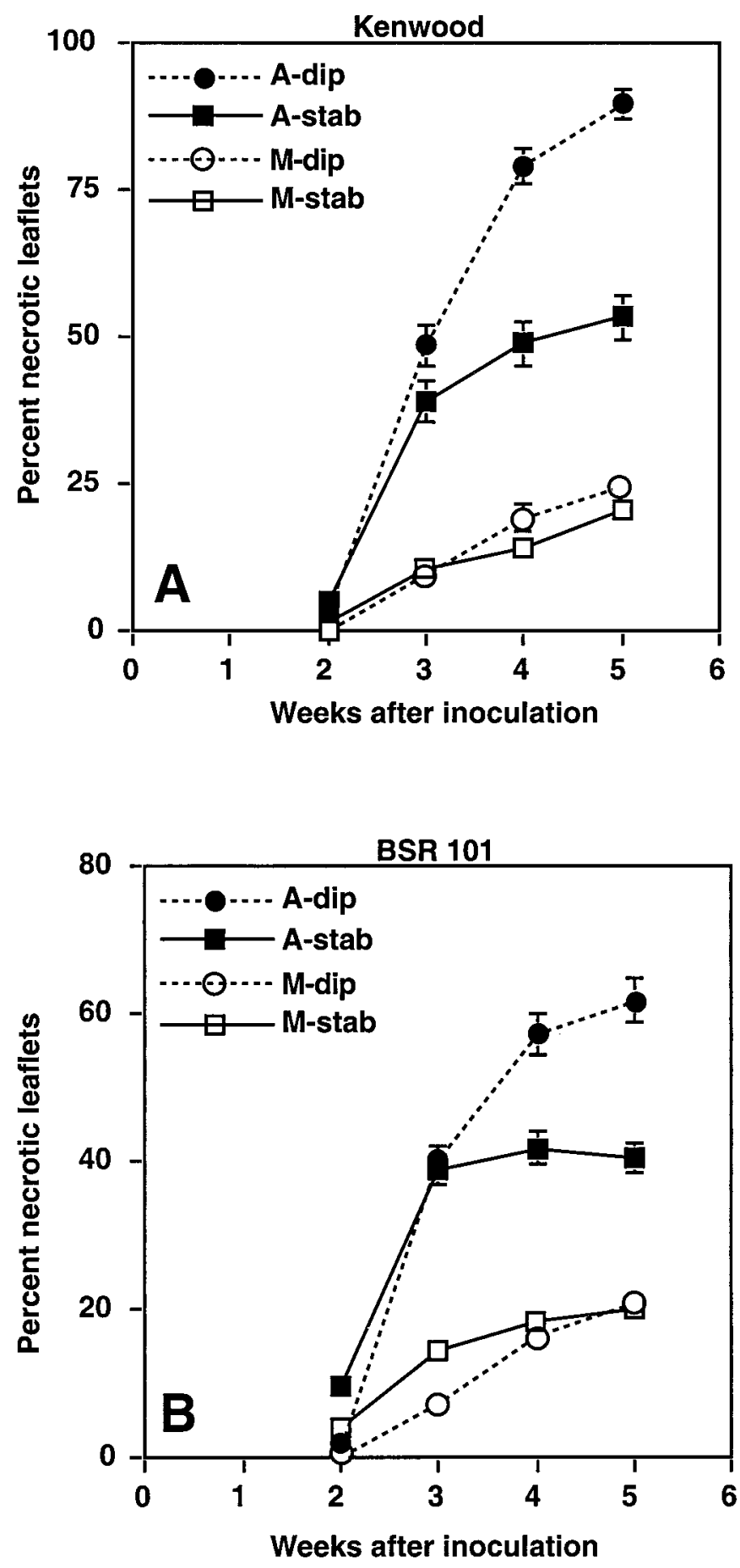

Fig. 4. Progress of leaflet necrosis in soybean cultivars A, Kenwood and $\mathbf{B}$, BSR101 inoculated by the root dip and stem (stab) inoculation methods using isolates of the aggressive and mild genotypes of Phialophora gregata. Error bars represent the standard errors of the means. bands in $(\mathrm{CAT})_{5}$ fingerprints and 30 bands in $(\mathrm{CAC})_{5}$ fingerprints were monomorphic across all isolates.

There were seven genotypes (unique combinations of seven polymorphic bands) identified among the 217 isolates tested (Table 1). Another genotype, A3, was identified as distinct from the A2 genotype based on the presence of the 9.0-kb (CAC) $)_{5}$ band (Fig. 1 ), but this band was not scoreable in all runs. A UPGMA analysis of these genotypes (Fig. 2) showed that two of the genotypes (referred to as M1 and M2) were closely related to each other and distinct from the other genotypes (referred to as A1, A2, A4, A5, and A6). The 6.4-kb (CAT) $)_{5}$ band (Table 1) appeared to be present only in the A genotypes. Isolates not possessing this band were either M1 or M2.

The average gene diversity values $(H)$ for $(\mathrm{CAT})_{5}$ bands (loci, with two alleles, present or absent) and $(\mathrm{CAC})_{5}$ were 0.0624 and 0.0090 for the entire population, 0.0032 and 0.0162 for the A genotypes only, and 0.0003 and 0 for the $\mathrm{M}$ genotypes only, respectively. When combining the data from the $(\mathrm{CAT})_{5}$ and $(\mathrm{CAC})_{5}$ fingerprinting, $H$ values of $0.0313,0.0107$, and 0.0003 were seen in the entire population, the A genotypes, and the $\mathrm{M}$ genotypes, respectively.

Geographic distribution of genotypes. The distribution of the 209 isolates of the seven genotypes is tallied in Table 2 and shown in Figure 3, in which it can be seen that the A genotypes were dominant in Ohio, Illinois, and the southeastern half of Iowa. The $\mathrm{M}$ genotypes were predominant in Missouri and the western half of Iowa, and all but two of the sampled isolates from Minnesota were the mild type. Another eight isolates from Wisconsin were also studied, but these were not randomly sampled. Four of these proved to be of the A1 genotype, three of the A2 genotype, and one of the M1 genotype (Table 2).

Inoculation techniques. Soybean cvs. Kenwood and BSR101 were inoculated by two techniques, a root dip method and a stem injection method, using nine isolates representing genotypes M1 (P30, P82, P92, and P137), A1 (P19, P21, P63, and P106), and A2 (P31). At 5 weeks postinoculation in both cultivars, there was no difference $(P=0.05$ based on linear contrasts) between A1 and A2 genotypes in the percent necrotic leaflets or in the linear extent of stem discoloration. Therefore, the data from these two genotypes were combined and contrasted against the M1 genotype.

No leaf symptoms were evident until week 2 , but regardless of inoculation method, most inoculated plants showed some leaf symptoms by week 3 , at which time the A genotypes caused dramatically more leaf symptoms than the $\mathrm{M}$ genotypes in both Kenwood and BSR101 seedlings (Fig. 4). Leaf symptoms tended

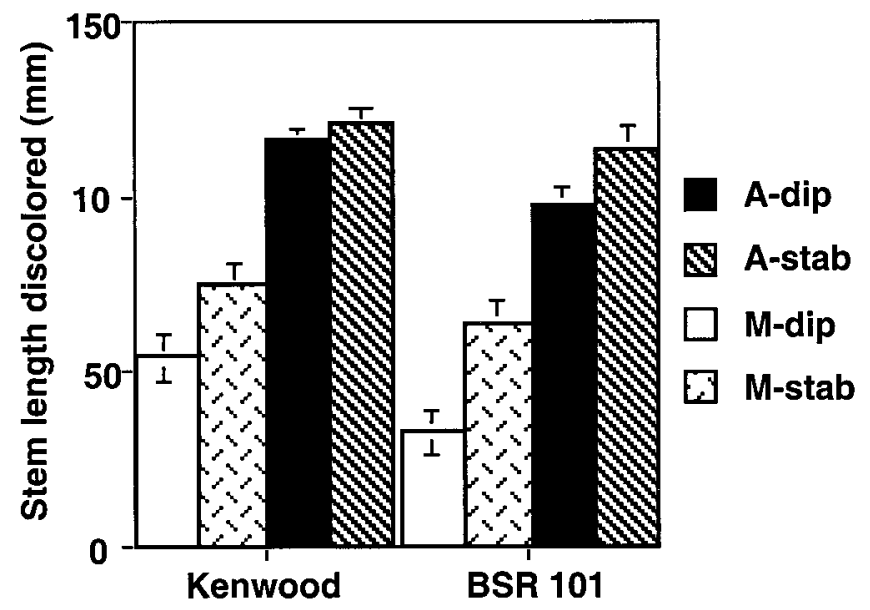

Fig. 5. Linear extent of stem discoloration in soybean cvs. Kenwood and BSR101 inoculated with isolates of the aggressive and mild genotypes of Phialophora gregata by the root dip and stem (stab) inoculation methods. Error bars represent the standard errors of the means. 
to increase slowly from week 3 to week 5 , except that plants dipinoculated with A genotype isolates showed a greater increase compared with M genotype isolates (Fig. 4). At week 5, there was a sharp contrast in the amount of leaf necrosis between A and M isolates $(P=0.0001)$ in both cultivars. At 5 weeks, there was no significant difference in the percent necrotic leaflets between the dip and stab methods on either cultivar using mild isolates, but with the A type isolates, the dip inoculation method resulted in significantly $(P=0.0001)$ more necrotic leaflets in both Kenwood and BSR101.

All isolates caused stem discoloration in both Kenwood and BSR101 seedlings at 5 weeks, but aggressive isolates caused significantly more stem discoloration than mild isolates $(P=0.001)$. There was no difference in the length of stem discoloration be- tween the root dip and stab inoculation methods, except when the mild isolates were inoculated into BRS101, in which case there was more $(P=0.01)$ stem discoloration when the stab method was used than when the dip method was used (Fig. 5).

From this study, it was concluded that the two inoculation procedures produce highly reproducible and comparable results. Because the stab inoculation was suitable for differentiating the susceptibility of the two cultivars to the $P$. gregata genotypes, we used this easier method for evaluating a larger population of isolates on Kenwood and BSR101.

Variation among genotypes on Kenwood and BSR101. An initial set of 49 isolates (24 later proved to be aggressive genotypes and 25 mild genotypes) was selected from among the northcentral population of $P$. gregata for comparing genotypes. These
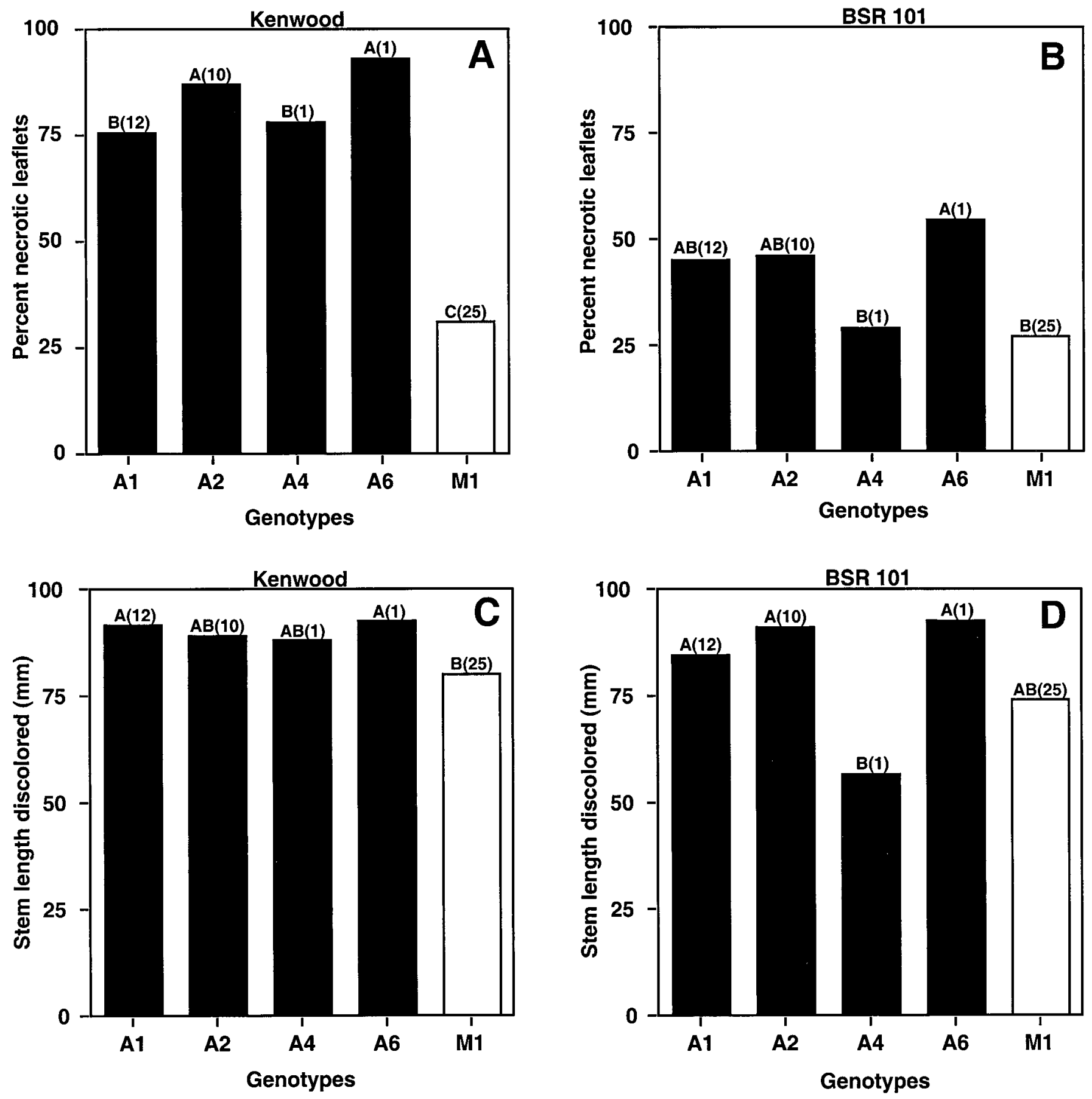

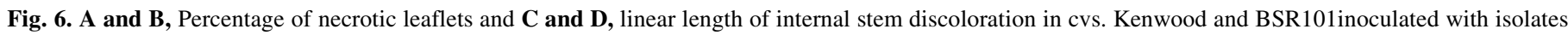

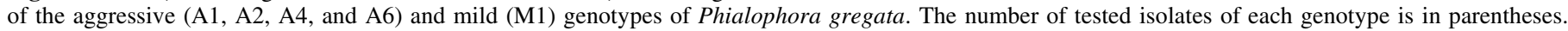
Different letters within each graph indicate significant difference $(P=0.05)$ according to Duncan's multiple range test. 
isolates were inoculated into soybean cvs. Kenwood and BSR101 by the stab method, and the percent necrotic leaflets and length of stem discoloration were evaluated at the end of 5 weeks. None of the soybean plants died after 5 weeks, but all of the inoculated plants showed vascular discoloration and leaflets with chlorosis and necrosis.

Percent necrotic leaflets on Kenwood was greater with A2 and A6 genotypes than with A1 and A4 genotypes, and the M1 genotype had less leaflet discoloration than any of the A genotypes (Fig. 6). There was less leaflet necrosis in BSR101 (Fig. 6A and B) than in Kenwood using the A type isolates, but there was no difference between cultivars inoculated with the M1 isolates. Differences among the genotypes in the amount of stem discoloration were not as dramatic as the differences in percent leaflet necrosis, except that the sole isolate of the A4 genotype caused less stem discoloration than the other aggressive genotypes in BSR101 (Fig. 6C and D).
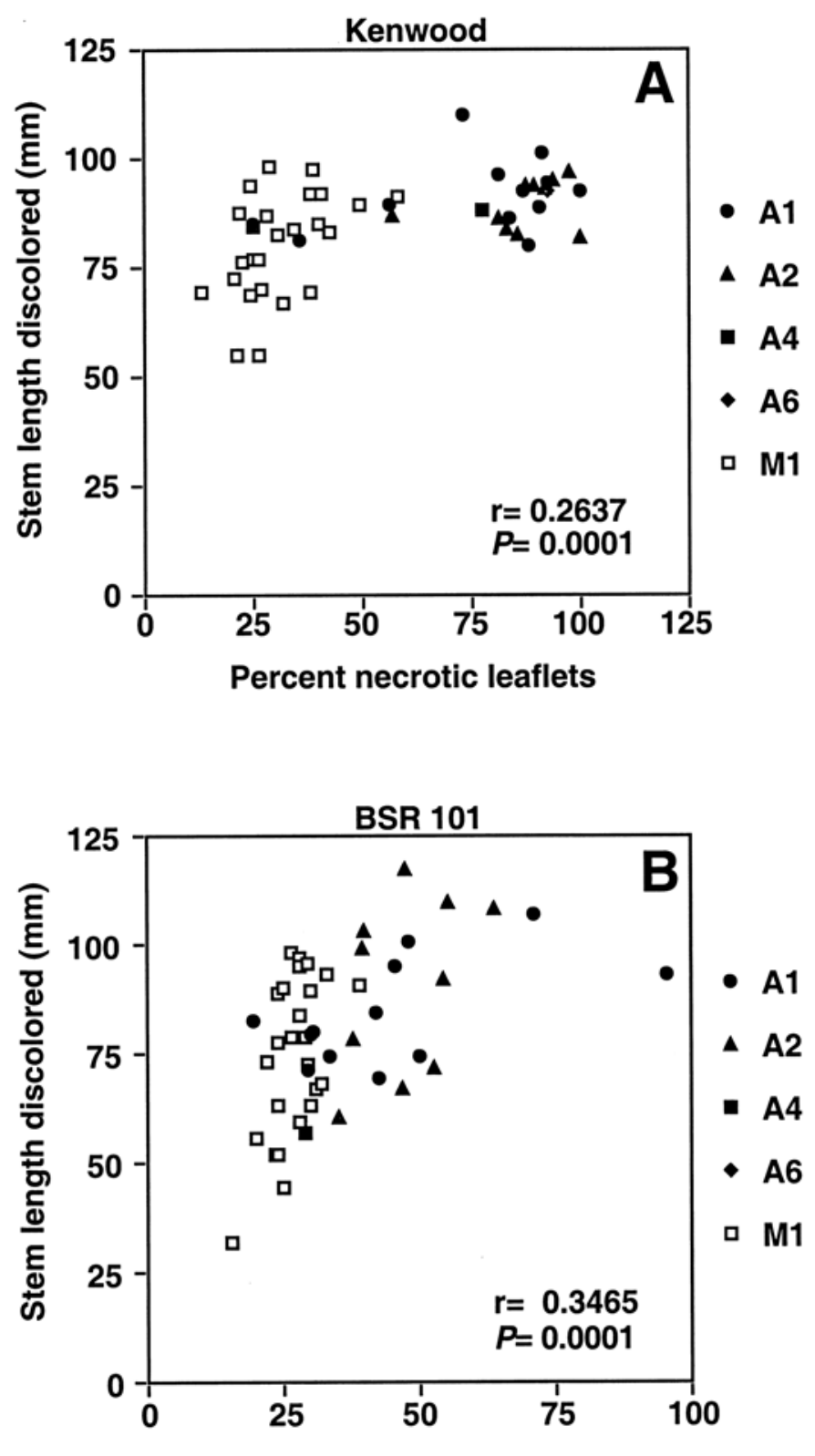

Percent necrotic leaflets

Fig. 7. Relationships between percent necrotic leaflets and linear length of stem discoloration in cultivars A, Kenwood and B, BSR101 inoculated with isolates of the aggressive (A1, A2, A4, and A6) and mild (M1) genotypes of Phialophora gregata.
On both Kenwood and BSR101, there was a correlation between the percent necrotic leaflets and length of stem discoloration caused by individual isolates (Fig. 7A and B). In both cultivars, all isolates of the $M$ genotype caused little leaflet necrosis, but the A genotype isolates differed greatly in the percentage of necrotic leaflets in both cultivars. Mild isolates tended to cause similar levels of leaflet necrosis and stem discoloration in the two cultivars (Fig. 8A and B), whereas most of the A genotype isolates caused more leaflet necrosis in Kenwood than in BSR101 (Fig. 8A). The greatest difference between isolates of the A and $\mathrm{M}$ genotypes was seen in the amount of leaflet necrosis in Kenwood, and to a lesser extent in BSR101. The frequency distribution of percent necrotic leaflets on each cultivar caused by the isolates of the $\mathrm{A}$ and $\mathrm{M}$ genotypes was clearly bimodal (Fig. 9A and B). There was more overlap in the frequency distributions of the A and $\mathrm{M}$ genotypes in stem length discoloration than in percent necrotic leaflets (Fig. 9C and D).

$\boldsymbol{R} \boldsymbol{b} \boldsymbol{s}$ genes. Five cultivars with different backgrounds for resistance to BSR were inoculated with nine isolates of $P$. gregata representing three genotypes. Besides BSR101 and Kenwood, accessions PI 84946-2 (with the Rbs1 resistance gene), PI 437833
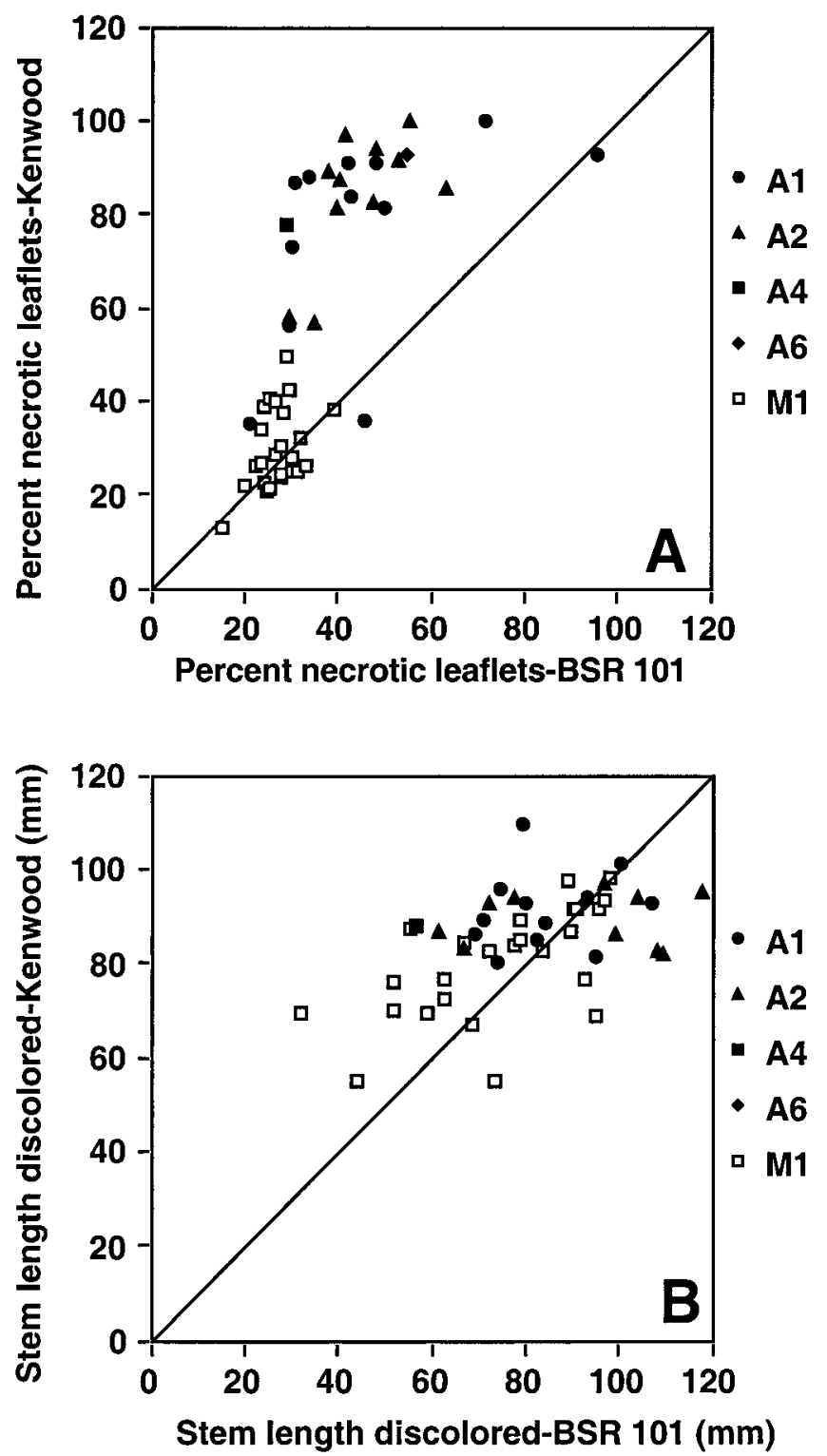

Fig. 8. Relative aggressiveness of isolates of the aggressive (A1, A2, A4, and A6) and mild (M1) genotypes of Phialophora gregata in A, leaflet necrosis and B, stem discoloration length on cvs. BSR101 and Kenwood. The diagonal line represents a 1:1 relationship. 
(with the Rbs 2 resistance gene), and PI 437970 (with the $R b s 3$ resistance gene) were inoculated with isolates P19, P21, P63, P106, P142 (A1 genotype), P28 (A2 genotype), and P82, P92, and P137 (M1 genotype). In all cultivars, there was less leaflet discoloration in plants inoculated with mild isolates compared with plants inoculated with aggressive isolates, although the difference was not great with PI 84946-2 (Fig. 10A). The M genotype isolates caused similar leaflet necrosis in each of the five cultivars tested, but the A genotype isolates caused the least leaflet necrosis in PI 84946-2 and the most in Kenwood (Fig. 10A). There was little variation among genotypes or among cultivars in the extent of stem discoloration (Fig. 10B).

ANOVA (Table 3) of the percent necrotic leaflets showed significant variance among genotypes and cultivars and a significant
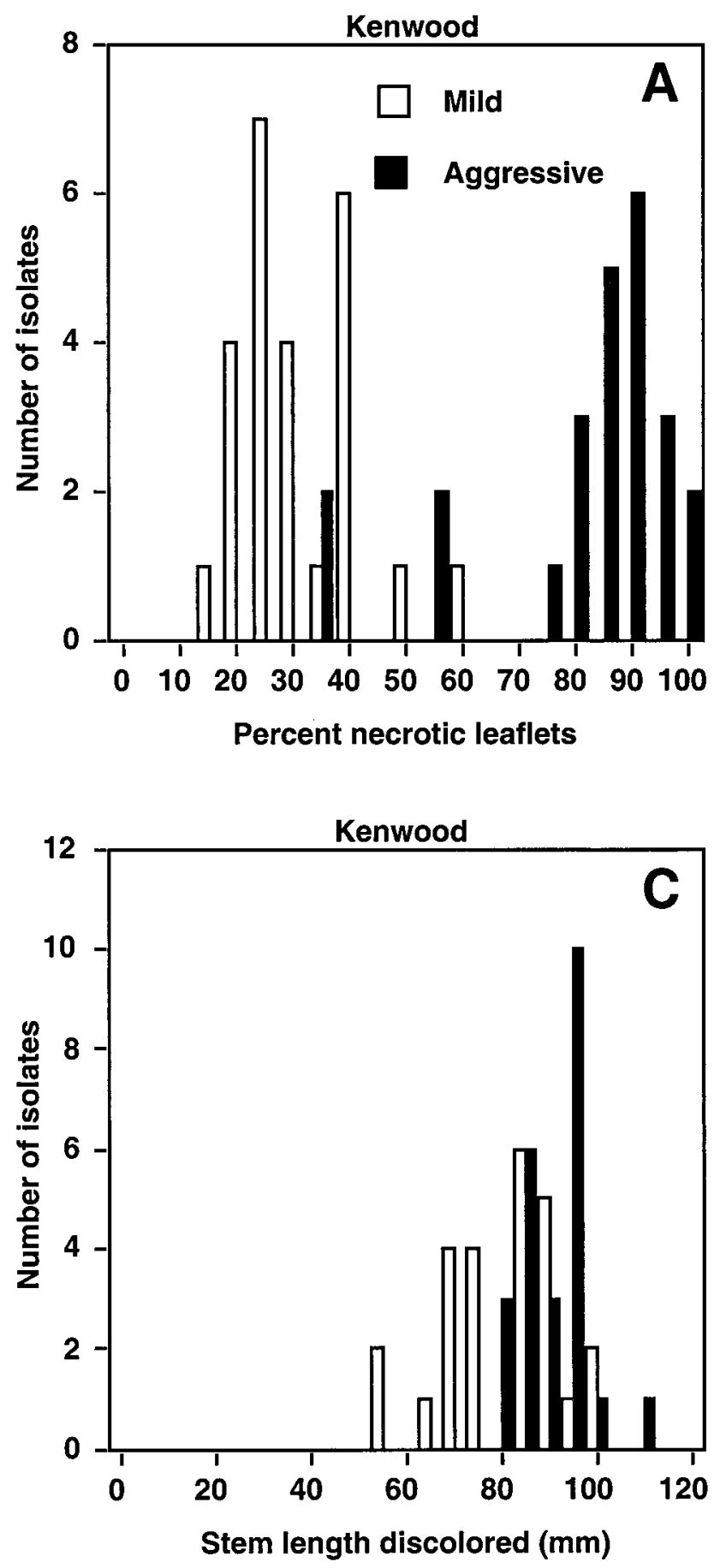

genotype $\times$ cultivar interaction. Less variation was seen in the amount of stem discoloration, in which genotypes of the pathogen did not differ, although there were differences among the cultivars, and there was a slightly significant genotype $\times$ cultivar interaction (Table 3).

Survey of 199 isolates in Kenwood. Because Kenwood appeared to be the best cultivar for contrasting the aggressiveness of isolates, this cultivar was selected for testing a larger population of $P$. gregata by stab inoculations. Isolates from the five northcentral states were selected to optimize their geographic distribution, with an emphasis on Iowa isolates. Isolates of four of the five A genotypes caused significantly more necrotic leaflets than isolates of mild genotypes (Fig. 11A). The A4 genotype was represented by only one isolate, and it caused a similar amount of
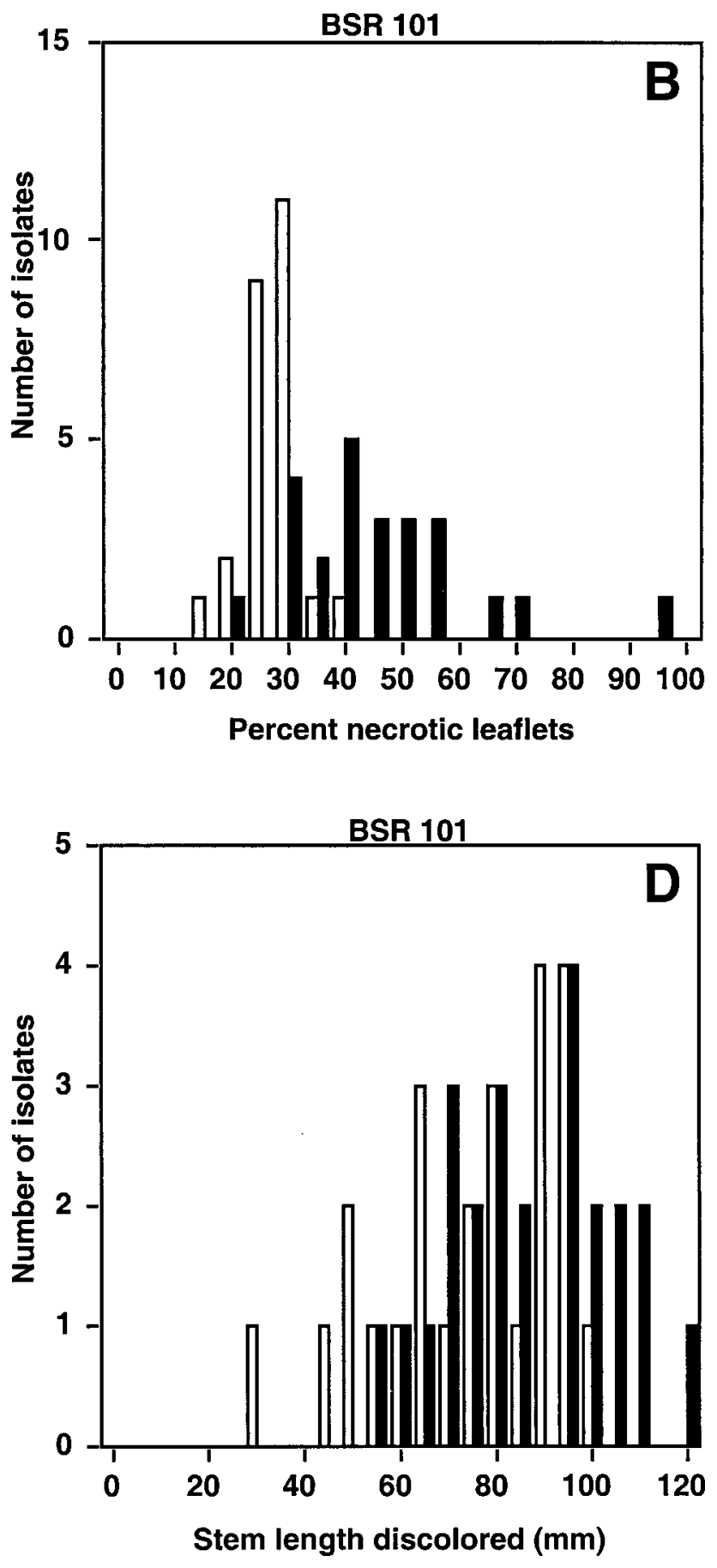

Fig. 9. A and B, Frequencies of the aggressive and mild isolates of Phialophora gregata in percent necrotic leaflets and $\mathbf{C}$ and $\mathbf{D}$, the linear length of stem discoloration in inoculated cvs. Kenwood and BSR101. 
leaflet necrosis as isolates of the mild genotypes. The amount of stem discoloration at 5 weeks did not differ significantly among isolates of the seven genotypes (Fig. 11B). The frequency distributions of the isolates of the $\mathrm{M}$ and $\mathrm{A}$ genotypes appear to have distinct, normal distributions, with rather limited overlap between the two in the percent necrotic leaflets (Fig. 12A) and more overlap in the length of discolored stem (Fig. 12B).

Stem diameter, leaflet necrosis, and stem discoloration. Data for the 199 isolates were used to correlate symptoms on the plants at the end of 5 weeks. There was a strong correlation between the percent necrotic leaflets and the length of stem discoloration with the 199 isolates (Fig. 13A). Also, the diameter of the stems at the end of the 5-week incubation period correlated negatively with the percent necrotic leaflets (Fig. 13B) and the length of discolored stem (Fig. 13C).

\section{DISCUSSION}

Little genetic variation was found in the north-central population of $P$. gregata based on fingerprinting with microsatellite probes $(\mathrm{CAT})_{5}$ and $(\mathrm{CAC})_{5}$. Seven unique fingerprint patterns were identified, and these could be grouped into two main genotypes based on UPGMA analyses of the fingerprint patterns. Isolates of these seven genotypes differed in aggressiveness to soybean. Isolates of the M1 genotype and the single, closely related isolate of the M2 genotype caused less leaf discoloration (necrosis) than isolates of the other five genotypes (A1, A2, A4, A5, and A6), and this difference was more pronounced in susceptible cv. Kenwood than in resistant cv. BSR101. There were less dramatic differences between the two groups based on the linear extent of stem discoloration. Isolates of A1 and A2 genotypes behaved similarly in inoculation tests.

The average gene diversity values found with the $(\mathrm{CAT})_{5}$ and $(\mathrm{CAC})_{5}$ markers are extremely low compared with other ascomycetes (14), but it should be noted that there is genetic variation within the A1, A2, and M1 genotypes of $P$. gregata f. sp. sojae. Several polymorphic bands were seen in the (CAT) $)_{5}$ fingerprints, but these bands were relatively faint and could not be scored consistently in all runs. Further, we (T. C. Harrington and J. Steimel, unpublished data) have developed polymerase chain reaction (PCR)-based microsatellite markers that distinguish many more genotypes of this fungus. Our data demonstrate more variation in $P$. gregata than was previously indicated (5), and if the populations are clonal, there are clearly more than two clones in the north-central region.

The two broad genotype groups found with our DNA fingerprinting markers correspond with the two genotypes found by Chen et al. (3) in the length of the intergenic spacer region (IGS) of the rDNA. Using their IGS primers, we (T. C. Harrington and J. Steimel, unpublished data) found that each of our A type isolates
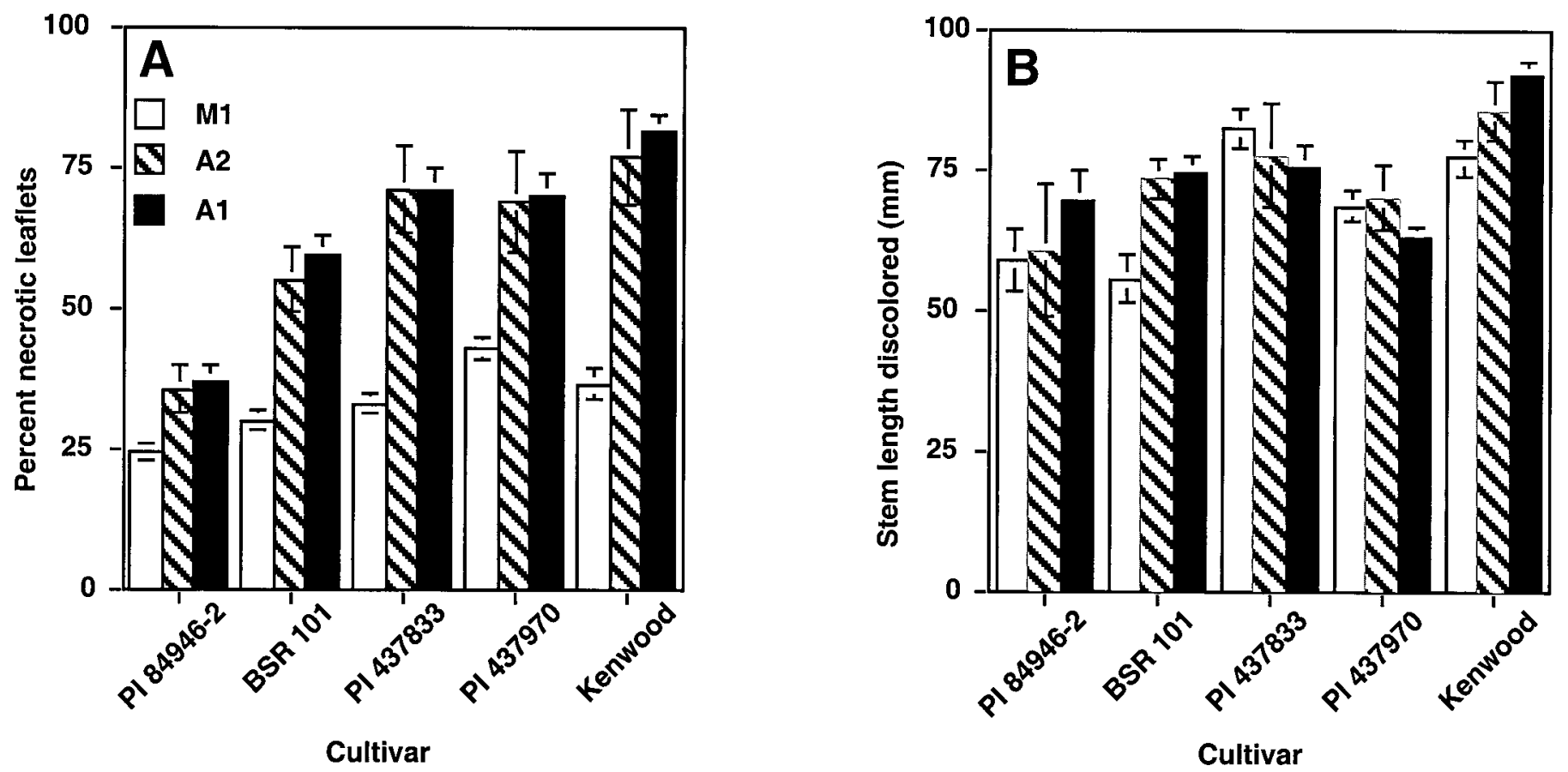

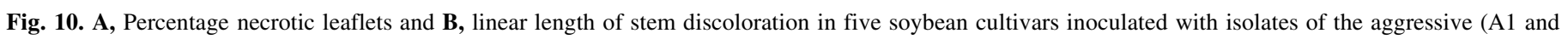
A2) and mild (M1) genotypes of Phialophora gregata.

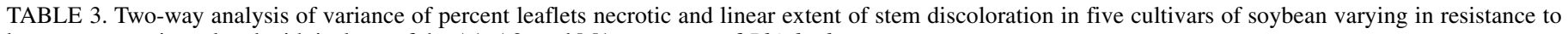
brown stem rot inoculated with isolates of the A1, A2, and M1 genotypes of Phialophora gregata

\begin{tabular}{|c|c|c|c|c|c|}
\hline Symptom & Source of variation & df & Mean square & $F$ value & $P>F$ \\
\hline \multirow[t]{5}{*}{ Leaflets necrotic } & Genotype & 2 & 3.2020 & 59.62 & 0.0001 \\
\hline & Cultivar & 4 & 1.0603 & 19.74 & 0.0001 \\
\hline & Genotype $\times$ cultivar & 8 & 0.1139 & 2.12 & 0.0372 \\
\hline & Experiment & 1 & 0.1158 & 2.16 & 0.1441 \\
\hline & Replicate & 2 & 0.0629 & 1.17 & 0.3126 \\
\hline \multirow[t]{5}{*}{ Stem discoloration } & Genotype & 2 & 756.86 & 2.80 & 0.0642 \\
\hline & Cultivar & 4 & $1,924.93$ & 7.11 & 0.0001 \\
\hline & Genotype $\times$ cultivar & 8 & 555.83 & 2.05 & 0.0439 \\
\hline & Experiment & 1 & 18.37 & 0.07 & 0.7948 \\
\hline & Replicate & 2 & $1,436.78$ & 5.31 & 0.0059 \\
\hline
\end{tabular}


had the 1,020-bp PCR product of their A genotype, while each of our $\mathrm{M}$ type isolates had the 830 -bp PCR product of their B genotype. Chen et al. (3) concluded that their A type corresponds with Gray's (9) type I or defoliating type, and their B type corresponds with Gray's type II or nondefoliating type. However, in contrast to Gray's (9) observations, both our A and M genotypes caused foliar symptoms. Differences between the A and M types in the linear extent of stem discoloration were not as pronounced as in the leaf discoloration, but the two symptoms were correlated with each other, and both symptoms correlated nega-
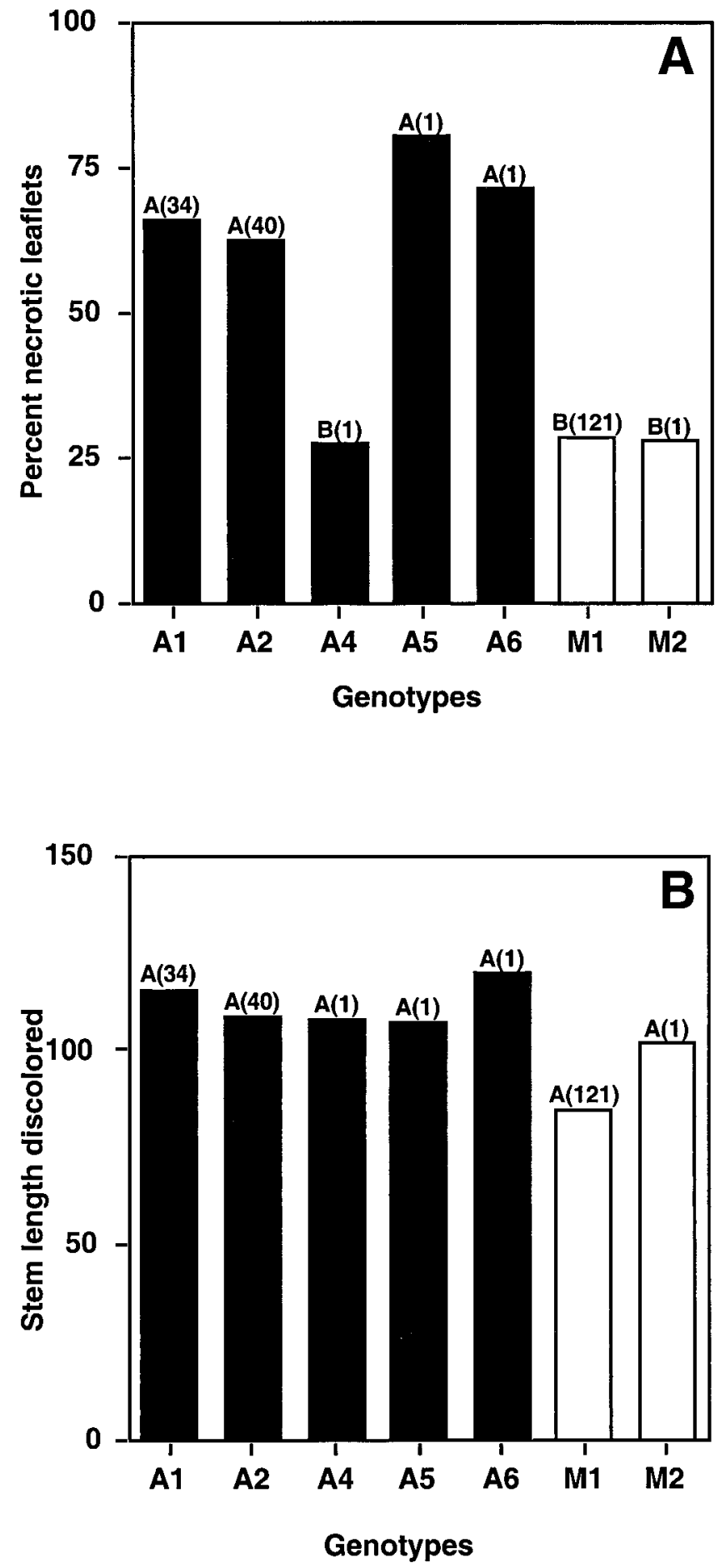

Fig. 11. A, Percent necrotic leaflets and B, stem discoloration in cv. Kenwood inoculated with the aggressive (A1, A2, A4, A5, and A6) and mild (M1 and M2) genotypes of Phialophora gregata. The number of isolates of each genotype tested are given on top of each bar. Bars with different letters are significantly different at $P=0.05$. tively with the stem diameter of the plants 5 weeks after inoculation. Other growth or yield data were not taken, but the strongest correlation among symptoms was between the percentage of leaflets that were necrotic and the stem diameter after 5 weeks. Thus, leaf symptoms correlated with growth more strongly than stem discoloration correlated with growth, and leaf symptoms appear more important than stem discoloration in screening for resistance or evaluating the effect of isolates on plant growth.

$P$. gregata is a vascular wilt pathogen that infects roots and moves systemically through the vascular system. Although there was no difference at 3 weeks postinoculation, root dip inoculations with the A type isolates induced more leaf discoloration than did the stab inoculations after 4 and 5 weeks. However, the extent of xylem discoloration was not significantly different between

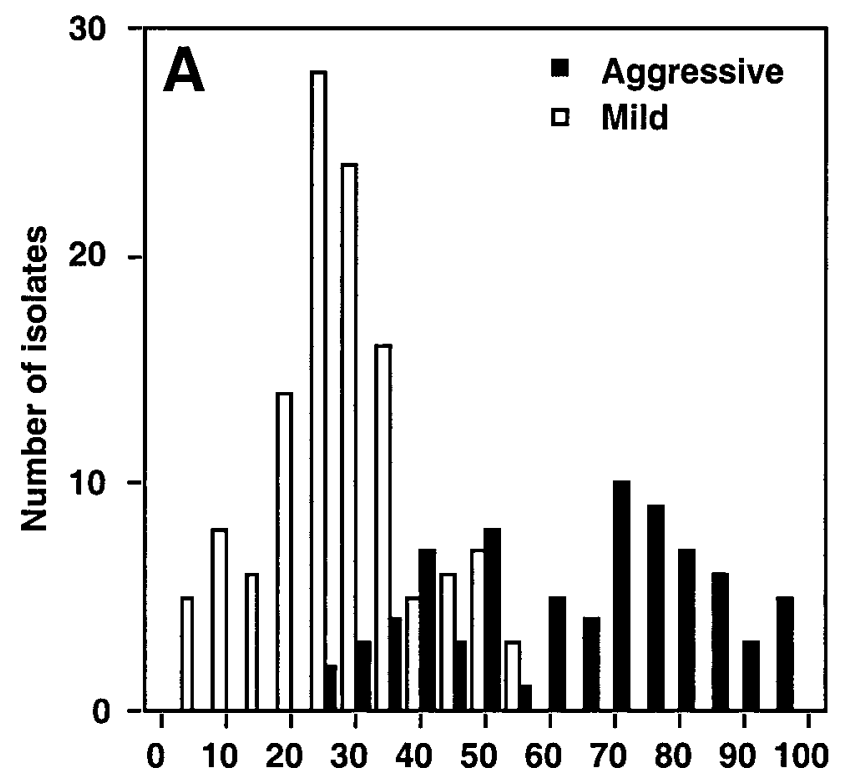

Percent necrotic leaflets

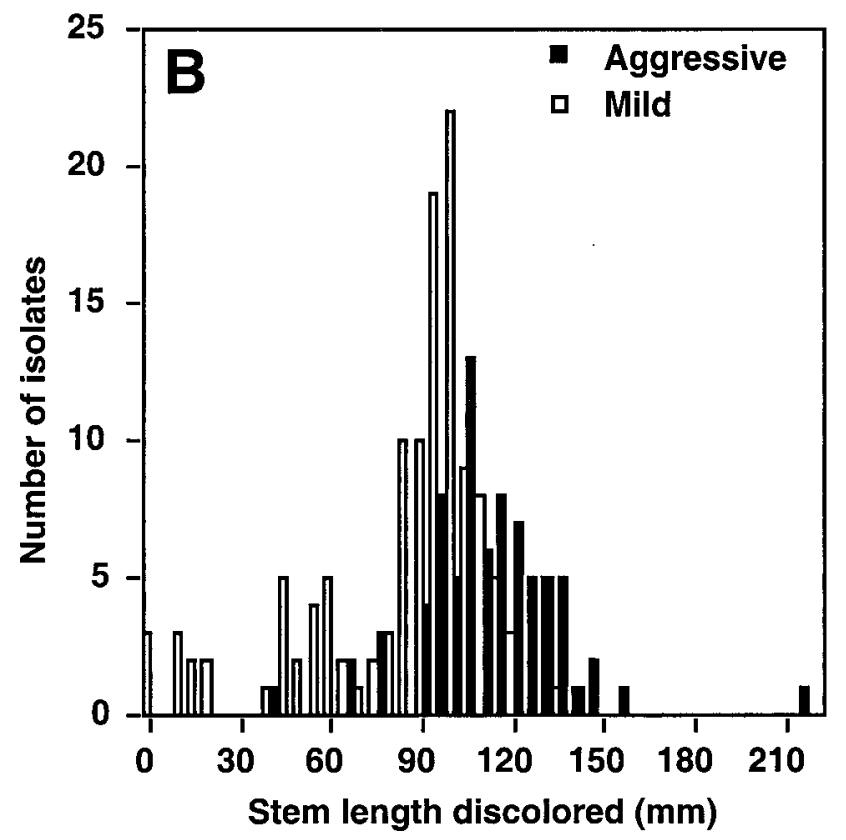

Fig. 12. Frequencies of isolates of the aggressive and mild genotypes of Phialophora gregata in $\mathbf{A}$, percent necrotic leaflets and $\mathbf{B}$, extent of stem discoloration in inoculated plants of soybean cv. Kenwood. 

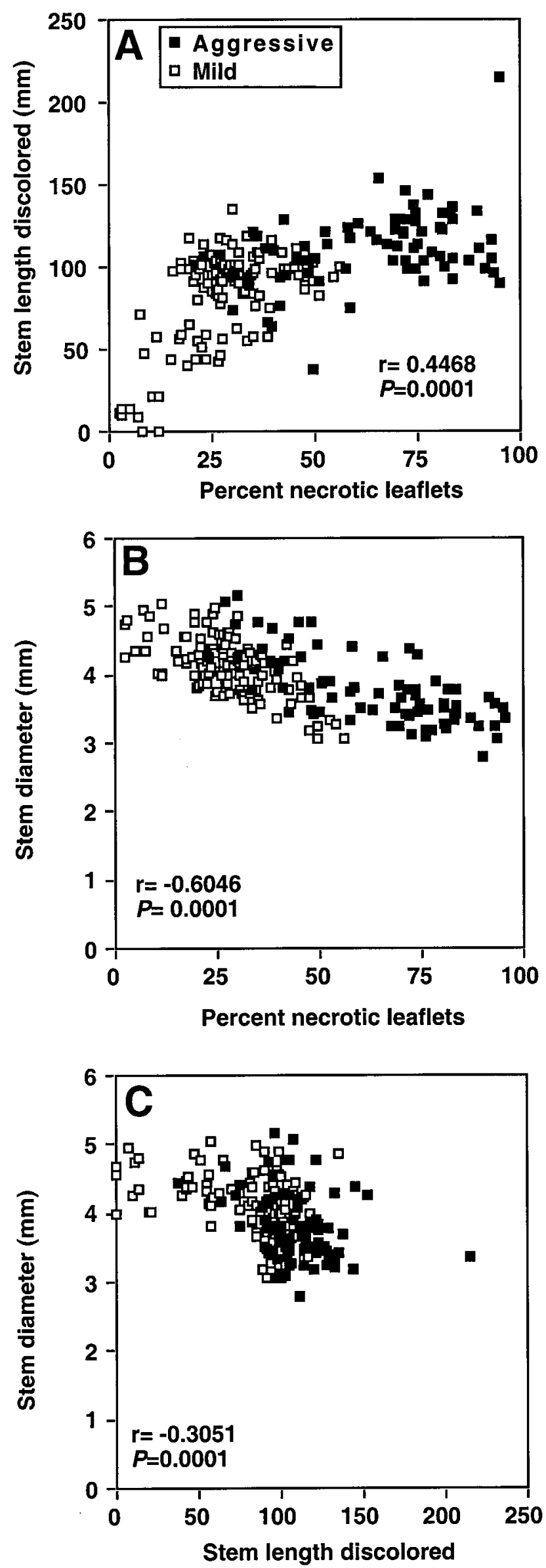

Fig. 13. Relationships among percent necrotic leaflets, stem discoloration, and stem diameter in soybean plants (cv. Kenwood) inoculated with isolates of the aggressive and mild genotypes of Phialophora gregata. plants inoculated with the root dip or stab techniques. The difference in leaf symptoms between the two inoculation methods with the A type isolates may be related to the extent of colonization by the isolates and the production of systemic toxins, which may be the cause of leaf chlorosis and necrosis. Gregatins have been reported $(11,18,19)$ to be phytotoxins produced by $P$. gregata, and the A type isolates may produce greater quantities of toxin or a more potent toxin than the $\mathrm{M}$ type isolates.

Differences in susceptibility between cv. Kenwood and the more resistant cv. BSR101 might also be related to phytotoxin sensitivity. Although the difference in the linear extent of stem discoloration between Kenwood and BSR101 was not great, much more leaf necrosis was observed in Kenwood than in the resistant BSR101. When the five soybean cultivars with various $R b s$ resistance genes were compared, greater differences in leaf symptoms than in stem discoloration were measured among the cultivars. Also, there was little difference in susceptibility of the cultivars to the $\mathrm{M}$ and $\mathrm{A}$ type isolates based on stem discoloration, but all cultivars showed greater leaf discoloration with the A type isolates than with the $M$ type isolates. The least foliar symptoms were seen in PI 84946-2, in which there was little difference between inoculations with the $\mathrm{A}$ and $\mathrm{M}$ type isolates, but this accession was similar to the other tested cultivars in the extent of stem discoloration. Thus, differences in aggressiveness and resistance appear most strongly expressed in leaf symptomatology, perhaps due to production and sensitivity to phytotoxins.

Although we can now recognize at least seven genotypes of $P$. gregata f. sp. sojae, only two phenotypes could be distinguished based on response to inoculations. The distribution frequencies of the severity of leaf symptoms caused by the tested isolates on both Kenwood and BSR101 were bimodal. There appear to be two major phenotypes of the pathogen in the north-central region, and these two phenotypes differ genetically. Further, there is a cultivar-pathogen genotype interaction in the degree of leaf symptomatology, with susceptible cv. Kenwood showing the greatest difference in leaf symptomatology among the five tested cultivars. Hughes et al. (16) likewise found two major phenotypes based on leaf symptomatology, and differences between their two phenotypes were more evident in susceptible than in resistant cultivars.

Although there is no uniformly applied terminology for such infraspecific variation in aggressiveness, the most appropriate nomenclature for designating the two phenotypes may be races, which was done in the special form of the fungus that attacks adzuki bean in Japan $(17,20)$. Two phenotypes of P. gregata $\mathrm{f}$. sp. adzukicola differing in the level of aggressiveness to certain cultivars of adzuki bean were designated as races A and B (21). Consistent with this nomenclature, we have designated the A phenotype as the aggressive race (race A) and the mild phenotype isolates as the mild race (race $\mathrm{M}$ ) of $P$. gregata $\mathrm{f}$. sp. sojae. The races can be identified by inoculating various cultivars of soybean and noting leaf symptoms, but the greatest difference in susceptibility to the races was seen in the most sensitive cultivar, Kenwood. Isolates can also be identified by genetic tests such as the DNA fingerprinting technique employed here or with PCR-based microsatellite markers (5). However, the easiest molecular technique currently available is the PCR-based technique for detection of the length differences in the IGS rDNA (3).

The geographic distribution of the 209 randomly sampled isolates in the north-central region shows that the A race is dominant in the east and the $\mathrm{M}$ race is dominant in the west. It is difficult to explain this difference in terms of climate or soils, but the eastern region tends to be more humid in the summer than the western region. Differences in the history of the introduction and spread of $P$. gregata within the north-central region might explain the differences in the current geographic distribution of the two races. It might be that the fungus is not native to the north-central region and that it was introduced here from Asia, perhaps on fine debris associated with imported soybean seed. The limited genetic varia- 
tion found with our fingerprinting technique might be the result of genetic bottlenecks in the two populations due to recent introductions of a limited number of strains into the north-central region. The apparently asexual nature of the fungus in the northcentral region would make the spread of the fungus essentially clonal. However, it should also be noted that the five genotypes identified for the aggressive race do not show a clear geographic differentiation; the A1 and A2 genotypes appear to be widespread from Iowa and Missouri to Ohio. The other three genotypes of race A were represented only by one isolate each. Thus, the geographic pattern shows differences between races but not necessarily differences in distribution of clonal genotypes.

Recognition of the aggressive and mild races of $P$. gregata has important implications for disease management and resistance development. First, variation in the severity of the disease appears to be explained at least in part by geography, and deployment of resistant germ plasm appears to be most needed where the aggressive race is most common, from eastern Iowa to Ohio, and particularly in Illinois. In regions such as Minnesota, where the pathogen is common $(15,33)$ but the population is comprised almost solely of the mild race, the disease should only need to be managed in fields where the aggressive race is present and causing significant yield loss. Second, screening for resistance should use the aggressive race of the pathogen. Germ plasm screened with isolates or natural inoculum of the mild race may not prove resistant when deployed in fields where the aggressive race is dominant. Such failures in the development and deployment of resistant cultivars have been reported in the past, and these failures may be due to differences between the two races of the pathogen. Third, resistance is best evaluated by the extent of leaf symptoms rather than the extent of stem discoloration, because the latter differs little among resistant and susceptible cultivars. Stem inoculation correlates well with root dip inoculations in symptom expression, but the stem inoculation method is much easier. We found very consistent results using the stem inoculation method and 15-day-old seedlings in the growth chamber, but greenhouse inoculations might also be effective. Field evaluations may be suitable, but we suggest that foliar symptoms rather than the linear extent of stem discoloration be used as the main evaluation criterion.

The data presented here show for the first time that there are more than two genotypes of $P$. gregata $\mathrm{f}$. sp. sojae, although at present only two phenotypes are apparent based on aggressiveness to soybean cultivars. The symptomatology of the inoculated plants suggests that foliar symptoms are better than stem discoloration for evaluating resistance or aggressiveness of isolates, and phytotoxins might explain some of the differences in leaf symptoms among cultivars and between the two races of the pathogen. Our random sample of isolates shows that the distributions of the A1 and A2 genotypes are similar, but the distribution of the M1 genotype is quite distinct, suggesting that the two races may occupy different ecological niches. We are conducting further genetic analyses of these populations to see if there are indications of gene flow between the two races and if the two races represent different species.

\section{ACKNOWLEDGMENTS}

This project was supported in part by the Iowa Soybean Promotion Board. We thank G. Tabor and C. Grau for provision of isolates.

\section{LITERATURE CITED}

1. Allington, W. B., and Chamberlain, D. W. 1948. Brown stem rot of soybean. Phytopathology 38:793-802.

2. Bachman, M. S., Nickell, C. D., Stephens, P. A., and Nickell, A. D. 1997. Brown stem rot resistance in soybean germ plasm from central China. Plant Dis. 81:953-956.

3. Chen, W., Grau, C. R., Adee, E. A., and Meng, X.-Q. 2000. Molecular marker identifying subspecific populations of soybean brown stem rot pathogen, Phialophora gregata. Phytopathology 90:875-883.

4. Chen, W., Gray, L. E., and Grau, C. R. 1996. Molecular differentiation of fungi associated with brown stem rot and detection of Phialophora gregata in resistant and susceptible soybean cultivars. Phytopathology 86:1140-1148.

5. Chen, W., Shi, X., and Chen, Y. C. 2002. Microsatellite markers and clonal genetic structure of the fungal pathogen Phialophora gregata. Mycol. Res. 106:194-202.

6. DeScenzo, R. A., and Harrington, T. C. 1994. Use of (CAT) $)_{5}$ as a DNA fingerprinting probe for fungi. Phytopathology 84:534-540.

7. Eathington, S. R., Nickell, C. D., and Gray, L. E. 1995. Inheritance of brown stem rot resistance in soybean cultivar BSR101. J. Hered. 86: 55-60.

8. Fehr, W. R., Caviness, C. E., Burmood, D. T., and Pennington, J. S. 1971. Stage of development descriptions for soybeans, Glycine max (L.) Merr. Crop Sci. 11:929-931.

9. Gray, L. E. 1971. Variation in pathogenicity of Cephalosporium gregatum isolates. Phytopathology 61:1410-1411.

10. Gray, L. E. 1989. Brown stem rot. Pages 29-30 in: Compendium of Soybean Diseases. 3rd ed. J. B. Sinclair and P. A. Backman, eds. The American Phytopathological Society, St. Paul, MN.

11. Gray, L. E., Gardner, H. W., Weisleder, D., and Leib, M. 1999. Production and toxicity of 2,3,-dihydro-5-hydroxy-2-methy-4H-1benzopyran-4-one by Phialophora gregata. Phytochemistry 50:13371340.

12. Gray, L. E., and Hepburn, A. G. 1992. Mitochondrial DNA restriction patterns of Phialophora gregata isolates from soybean and adzuki bean. Phytopathology 82:211-215.

13. Hanson, P. M., Nickell, C. D., Gray, L. E., and Sebastian, S. A. 1988. Identification of two dominant genes conditioning brown stem rot resistance in soybean. Crop Sci. 28:41-43.

14. Harrington, T. C., Steimel, J., and Kile, G. A. 1998. Genetic variation in three Ceratocystis species with outcrossing, selfing and asexual reproductive strategies. Eur. J. For. Pathol. 28:217-226.

15. Harrington, T. C., Steimel, J., Workneh, F., and Yang, X. B. 2000. Molecular identification of fungi associated with vascular discoloration of soybean in the north central United States. Plant Dis. 84:83-89.

16. Hughes, T. J., Chen, W., and Grau, C. R. 2002. Pathogenic characterization of genotypes A and B of Phialophora gregata f. sp. sojae. Plant Dis. 86:729-735.

17. Kobayashi, K., Nondo, N., Tanaka, H., and Ui, T. 1980. Differences in the virulence of type A and type B isolates of Cephalosporium gregatum. Ann. Phytopathol. Soc. Jpn. 46:253-255.

18. Kobayashi, K., and Tado, U. 1977. Wilt-inducing antibiotic compounds produced by Cephalosporium gregatum. Physiol. Plant Pathol. 11: 55-60.

19. Kobayashi, K., and Tado, U. 1980. Production of gregatins by an Iowa isolate of Cephalosporium gregatum, the cause of brown stem rot of soybeans in U.S.A. Ann. Phytopathol. Soc. Jpn. 46:256-257.

20. Kobayashi, K., Yamamoto, H., Negishi, H., and Ogoshi, A. 1991. Forma specialis differentiation of Phialophora gregata isolates from adzuki bean in Japan and from soybean in the United States. Ann. Phytopathol. Soc. Jpn. 57:225-231.

21. Kondo, N., Fujita, S., Murata, K., and Ogoshi, A. 1998. Detection of two races of Phialophora gregata f. sp. adzukicola, the causal agent of adzuki bean brown stem rot. Plant Dis. 82:928-930.

22. Meng, X. Q., and Chen, W. 2001. Applications of AFLP and ISSR techniques in detecting genetic diversity in the soybean brown stem rot pathogen Phialophora gregata. Mycol. Res. 105:936-940.

23. Mengistu, A., and Grau, C. R. 1986. Variation in morphological, cultural, and pathological characteristics of Phialophora gregata and Acremonium sp. recovered from soybean in Wisconsin. Plant Dis. 70:1005-1009.

24. Mengistu, A., Grau, C. R., and Gritton, E. T. 1986. Comparison of soybean genotypes for resistance to and agronomic performance in the presence of brown stem rot. Plant Dis. 70:1095-1098.

25. Mengistu, A., Tachibana, H., and Grau, C. R. 1991. Selective medium for isolation and enumeration of Phialophora gregata from soybean straw and soil. Plant Dis. 75:196-199.

26. Nelson, R. L., Nickell. C. D., Orf, J. H., Gritton, E. T., Grau, C. R., and Kennedy, C. W. 1989. Evaluating soybean germplasm for brown stem rot resistance. Plant Dis. 73:110-114.

27. Phillips, D. V. 1973. Variation in Phialophora gregata. Plant Dis. Rep. 57:1063-1065.

28. Schnider, R. W., Sinclair, J. B., and Gray, L. E. 1972. Etiology of Cephalosporium gregatum in soybean. Phytopathology 62:346-349.

29. Sills, G. R., Gritton, E. T., and Grau, C. R. 1991. Differential reactions of soybean genotypes to isolates of Phialophora gregata. Plant Dis. 
75:687-690.

30. Waller, R. S., Nickell, C. D., Drzycmski, D. L., and Miller, J. E. 1991. Genetic analysis of the inheritance of brown stem rot resistance in soybean cultivar Asgrow A3733. J. Hered. 82:412-417.

31. Willmot, D. B., and Nickell, C. D. 1989. Genetic analysis of brown stem rot resistance in soybean. Crop Sci. 29:672-674.

32. Willmot, D. B., Nickell, C. D., and Gray, L. E. 1989. Physiologic specialization of Phialophora gregata on soybean. Plant Dis. 73:
290-294

33. Workneh, F., Tylka, G. L., Yang, X. B., Faghihi, J., and Ferris, J. M. 1999. Regional assessment of soybean brown stem rot, Phytophthora sojae, and Heterodera glycines using area-frame sampling: Prevalence and effects of tillage. Phytopathology 89:204-211.

34. Wrather, J. A., Stienstra, W. C., and Koenning, S. R. 2001. Soybean disease loss estimates for the United States from 1996 to 1998. Can. J. Plant Pathol. 23:115-121. 